\title{
Successful surgical treatment of chronic ischemic mitral regurgitation achieves left ventricular reverse remodeling but does not affect right ventricular function
}

\author{
Francesco Onorati, MD, ${ }^{\mathrm{a}}$ Giuseppe Santarpino, MD, ${ }^{\mathrm{a}}$ Domenico Marturano, MD, ${ }^{\mathrm{a}}$ \\ Antonino S. Rubino, MD, ${ }^{\mathrm{a}}$ Eugenia Pasceri, MD, ${ }^{\mathrm{b}}$ Stefania Zinzi, MD,${ }^{\mathrm{b}}$ Giuseppina Mascaro, MD, \\ Lucia Cristodoro, MD, ${ }^{\mathrm{a}}$ and Attilio Renzulli, MD, PhD, FETCS ${ }^{\mathrm{a}}$
}

Objective: To evaluate left-sided and right-sided heart echocardiographic results after restrictive mitral annuloplasty in chronic ischemic mitral regurgitation.

Methods: Left atrial diameter, left ventricular end-diastolic diameter, left ventricular end-systolic diameter, left
ventricular ejection fraction, left ventricular indexed mass, coaptation depth, transmitral mean gradient, systolic
pulmonary arterial pressure, tricuspid annular plane systolic excursion, right ventricular ejection fraction, and tri-
cuspid insufficiency grading were evaluated preoperatively, postoperatively, at 6 months, and at the end of the
follow-up period in 64 patients undergoing restrictive mitral annuloplasty and coronary artery bypass grafting.
Recurrence of chronic ischemic mitral regurgitation was defined as $2+4+$ grade or greater mitral regurgitation
at any time postoperatively.

Results: Twenty-two months of freedom from recurrent chronic ischemic mitral regurgitation was $58.2 \% \pm$ $9.8 \%$. Recurrent chronic ischemic mitral regurgitation did not lead to reverse remodeling of left atrial diameter, left ventricular end-diastolic diameter, left ventricular end-systolic diameter, and ventricular indexed mass ( $P=$ not significant), with increased coaptation depth, parallel to follow-up chronic ischemic mitral regurgitation worsening. Effective restrictive mitral annuloplasty induced reverse remodeling of left ventricular end-diastolic diameter, left ventricular end-systolic diameter, and ventricular indexed mass, improved left ventricular ejection fraction, shortened coaptation depth, and improved mean gradient $(P \leq .014)$. Recurrent chronic ischemic mitral regurgitation in patients without tricuspid surgery prevented improvements of systolic pulmonary arterial pressure, tricuspid annular plane systolic excursion, right ventricular ejection fraction, worsening New York Heart Association $(P=.003)$, and daily diuretic need $(P=.008)$, whereas effective restrictive mitral annuloplasty progressively improved tricuspid insufficiency grading, systolic pulmonary arterial pressure, right ventricular ejection fraction, tricuspid annular plane systolic excursion, New York Heart Association, and diuretic need $(P \leq .013)$. Patients undergoing tricuspid annuloplasty did not show any improvement of systolic pulmonary arterial pressure, right ventricular ejection fraction, and tricuspid annular plane systolic excursion regardless of the recurrence of chronic ischemic mitral regurgitation ( $P=$ not significant), although effective restrictive mitral annuloplasty improved tricuspid insufficiency grading, New York Heart Association, and daily diuretic need $(P \leq .010)$.

Conclusion: Effective restrictive mitral annuloplasty induces reverse left ventricular remodeling. Absence of recurrent chronic ischemic mitral regurgitation improves tricuspid insufficiency grading, systolic pulmonary arterial pressure, right ventricular ejection fraction, tricuspid annular plane systolic excursion, New York Heart Association, and diuretic need in patients who do not undergo tricuspid surgery, but only tricuspid insufficiency grading, New York Heart Association, and daily diuretic need in patients who undergo tricuspid surgery.

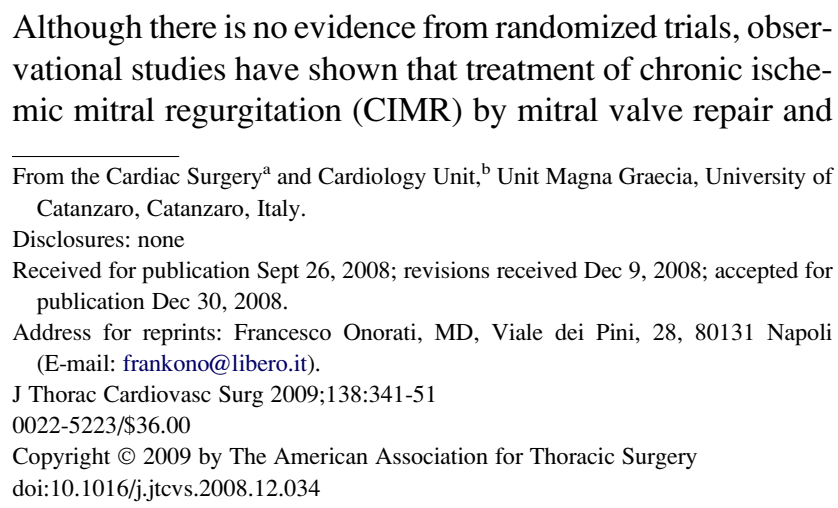

Although there is no evidence from randomized trials, observational studies have shown that treatment of chronic ischemic mitral regurgitation (CIMR) by mitral valve repair and

coronary artery bypass grafting (CABG) leads to a better outcome than $\mathrm{CABG}$ alone. ${ }^{1}$ It has been demonstrated that restrictive mitral annuloplasty (RMA) $+\mathrm{CABG}$ has a positive effect on short-term follow-up reverse remodeling. ${ }^{2}$ Debate continues, however, with regard to survival benefits, ${ }^{3}$ which is also reflected in the latest American College of Cardiology/American Heart Association Guidelines. ${ }^{4}$ Nevertheless, despite that the results of mitral repair for CIMR have improved over the last 20 years, ongoing dissatisfaction with outcomes and recurrences have yielded many different approaches to CIMR. ${ }^{5}$ Accordingly, the long-term efficacy of RMA is still unclear, and recurrence of CIMR has been 


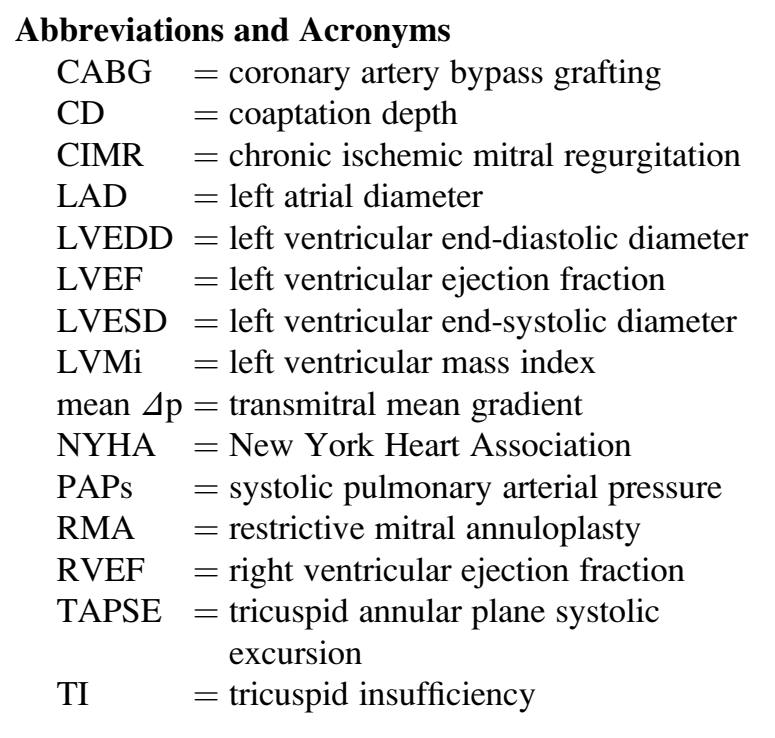

predominantly related to progressive left ventricular dilation and responsible for recurrent congestive heart failure and follow-up morbidity and mortality. ${ }^{6}$ Few literature data exist regarding mid- to long-term echocardiographic results after RMA. $^{7}$ Finally, despite the supposed beneficial effects of RMA in terms of congestive heart failure and left ventricular reverse remodeling, little is known about the fate of the right ventricle after RMA, although a recent study has proven RMA to act as a native mitral stenosis. ${ }^{8}$

This study evaluates the midterm clinical and echocardiographic results of a consecutive series of patients undergoing $\mathrm{RMA}+\mathrm{CABG}$ for CIMR, focusing on left and right ventricular function and remodeling, with subgroup analysis in patients with tricuspid surgery.

\section{MATERIALS AND METHODS Patients and Surgery}

Between August 2004 and September 2007, 66 consecutive patients who were admitted with CIMR and underwent RMA + CABG with at least 6 months of postoperative follow-up were enrolled. Institutional review board approved conducting this study and waived the need for individual consent. CIMR was defined as mitral regurgitation occurring more than 1 week after myocardial infarction with 1 or more left ventricular segmental wall motion abnormalities, significant coronary disease in the territory supplying the wall motion abnormality, and structurally normal mitral valve leaflets and chordae tendinae. ${ }^{5}$ Therefore, patients with organic mitral disease (eg, myxomatous, rheumatic) were excluded from the study. All patients had coronary artery disease and CIMR grade $3+$ or $4+$ at preoperative echocardiography (semiquantitatively from color-flow Doppler). Patients demonstrating 2+ CIMR underwent further provocative intraoperative testing (rapid infusion of volume until the wedge pressure reached 16 to $18 \mathrm{~mm} / \mathrm{Hg}$ or phenylenephrine administration until mean arterial pressure reached $100 \mathrm{~mm} / \mathrm{Hg})^{9}$ and were enrolled whenever $3+$ to $4+$ mitral regurgitation was shown.

CIMR was always caused by post-infarction restrictive systolic leaflet motion (Carpentier type IIIb) (Table 1), severe annular dilation resulting from ischemic dilated cardiomyopathy (Carpentier type I), or a combination
TABLE 1. Preoperative and intraoperative data

\begin{tabular}{lcc}
\hline \multicolumn{1}{c}{ Variables } & No. of patients & $\%$ (global population) \\
\hline Age (y) & $69.9 \pm 2.3$ & - \\
Sex (male) & 41 & $64.1 \%$ \\
NYHA & $3.4 \pm 0.6$ & - \\
Canadian class score & $3.1 \pm 0.6$ & - \\
Diabetes & 30 & $46.9 \%$ \\
Hypertension & 17 & $26.6 \%$ \\
COPD & 39 & $60.9 \%$ \\
Left main stem disease & 46 & $71.9 \%$ \\
Previous AMI & 28 & $43.8 \%$ \\
Recent (<4 wk) AMI & 36 & $56.3 \%$ \\
Anterior AMI & 16 & $25.0 \%$ \\
Posterior AMI & 38 & $59.4 \%$ \\
Anterior + posterior AMI & 10 & $15.6 \%$ \\
Emergency & 2 & $3.1 \%$ \\
Non-STEMI & 36 & $56.3 \%$ \\
STEMI & 1 & $1.6 \%$ \\
No. of CABG surgeries & $2.3 \pm 1.1$ & - \\
LITA CABG & 64 & $100 \%$ \\
RA CABG & 12 & $18.8 \%$ \\
ACC time & $73.3 \pm 4.1$ & - \\
CPB time & $135.5 \pm 12.2$ & - \\
Tricuspid annuloplasty & 16 & $25 \%$ \\
\hline
\end{tabular}

NYHA, New York Heart Association; COPD, chronic obstructive pulmonary disease; $A M I$, acute myocardial infarction; STEMI, ST elevation myocardial infarction; $C A B G$, coronary artery bypass graft; LITA, left internal thoracic artery; $R A$, radial artery; $A C C$, aortic crossclamp; $C P B$, cardiopulmonary bypass.

of both (Carpentier type I + IIIb) (Table 1). Patients with concomitant surgery (eg, surgical ventricular restoration, papillary sling, aortic valve surgery), apart from tricuspid annuloplasty, were excluded from the study. Accordingly, tricuspid regurgitation $2+$ or greater or tricuspid regurgitation less than $2+$ in the presence of dilated tricuspid annulus exceeding $21 \mathrm{~mm} / \mathrm{m}^{2}$ indexed to body surface area at transthoracic echocardiography indicated concomitant tricuspid annuloplasty. ${ }^{10}$

All patients had symptoms of heart failure, and the majority presented New York Heart Association (NYHA) class III or IV (Table 1). Mean logistic European System for Cardiac Operative Risk Evaluation was $10.8 \pm 3.1$. The diagnosis of chronic obstructive pulmonary disease was based on the Summit database definition: Each patient required treatment for chronic pulmonary compromise or had a forced expiratory volume in 1 second less than $75 \%$ of predicted value or a forced expiratory volume in 1 second to forced expiratory vital capacity less than 0.7 at preoperative spirometry. Baseline characteristics are presented in Table 1.

Surgery was performed by the same surgeon (A.R.) in all cases through a median sternotomy. The ascending aorta was always cannulated, and venous return was always accomplished through a double caval cannulation. All patients underwent left internal thoracic artery to the left anterior descending grafting. The radial artery was used in 18 patients and always harvested as a pedicle with an ultrasonic scalpel (Ethicon Endo-Surgery, Cincinnati, Ohio). Saphenous veins were always harvested from the best side, as detected by preoperative echo-Doppler scanning. All grafts underwent intraoperative transit-time analysis, and unsatisfactory results always led to redo CABG. ${ }^{11}$ The mitral valve was exposed through a longitudinal atriotomy along the Waterston's groove in all patients. Ring size (Carpentier-Edwards Physio ring; Edwards Lifesciences, Irvine, Calif or CarpentierMcCarthy-Adams ring, Edwards Lifesciences) was determined after careful measurement of the height of the anterior leaflet and intertrigonal distance, and then downsizing by 2 sizes (ie, size 26 when measuring 30). Complete symmetric rings (Carpentier-Edwards Physio ring) were preferred when 
CIMR was predominantly caused by annular dilation (Carpentier type I), and complete asymmetric rings (Carpentier-McCarthy-Adams ring) were preferred when inferior or posterolateral infarction caused restrictive systolic leaflet motion (Carpentier type IIIb). Tricuspid annuloplasty was always accomplished with a Carpentier Edwards MC3 ring (Edwards Lifesciences). By using the Carpentier's measurement technique, the appropriate ring size was selected on the basis of the length of the attachments of the tricuspid septal leaflet and the surface area of the anterior leaflet, and then downsized by at least 1 measure. Ring implantation was performed by placing 8 to 10 mattress sutures through the tricuspid annulus around the orifice, avoiding the area of atrioventricular conduction tissue.

Cardiopulmonary bypass was standardized: a Dideco (Mirandola, Modena, Italy) tubing set, which included a $40-\mu \mathrm{m}$ filter, Stockert roller pump (Stockert Instrumente, Munich, Germany), and hollow fiber membrane oxygenator (Dideco D903 Avant, Mirandola). Myocardial protection was always achieved with intermittent antegrade and retrograde hyperkalemic blood cardioplegia.

\section{Anticoagulation Protocol}

It was institutional policy to start 4000 IU low molecular weight heparin (nadroparin) 2 times per day 8 hours after surgery. Warfarin therapy was started on the second postoperative day, targeted to an international normalized ratio between 2.0 and 3.0 in patients with sinus rhythm and between 2.5 and 3.5 in patients with atrial fibrillation, until the third postoperative month. Oral antiplatelet therapy (acetylsalicylic acid $150 \mathrm{mg} / \mathrm{d}$ ) was started thereafter.

\section{Echocardiography}

Echocardiography was always accomplished by the same 3 cardiologists, using a VIVID 7 Pro ultrasound machine (GE Technologies, Milwaukee, Wis). All patients underwent preoperative transthoracic and transesophageal echocardiography. Transthoracic echocardiographic evaluation consisted of standard echocardiography examination, including grading of severity of CIMR (semiquantitatively from color-flow Doppler), left atrial diameter (LAD), left ventricular end-diastolic diameter (LVEDD), left ventricular end-systolic diameter (LVESD), left ventricular ejection fraction (LVEF), left ventricular mass index (LVMi), coaptation depth (CD), transmitral mean gradient (mean $\Delta \mathrm{p}$ ), systolic pulmonary arterial pressure (PAPs), tricuspid annular plane systolic excursion (TAPSE), and tricuspid insufficiency (TI) grading. Apical 4-chamber view was accomplished to measure severity of CIMR, LAD, LVEF (Simpson's method), CD, and transmitral mean $\Delta \mathrm{p}$. Parasternal long-axis view was used to measure LVEDD and LVESD by M-mode.

The severity of CIMR was determined by the ratio of maximum color Doppler regurgitant jet area to left atrial area. CIMR grade was estimated as trivial, mild, moderate, or severe on the basis of ratios of $0 \%$ to $10 \%$, $10 \%$ to $20 \%, 20 \%$ to $40 \%$, and greater than $40 \%$, respectively. ${ }^{10}$ Mean preoperative CIMR was $3.4 \pm 0.6$ (range $2+$ to $4+$ ). Indexed left ventricular mass was calculated according to Devereux's formula. ${ }^{12} \mathrm{TI}$ was evaluated using the apical 4-chamber view. TI was graded as trace (1+), mild (2+), moderate (3+), or severe (4+) when the jet area occupied less than $10 \%$, $10 \%$ to $20 \%, 20 \%$ to $33 \%$, or more than $33 \%$ of the right atrial area, respectively. ${ }^{10}$ Mean preoperative TI was $2.0 \pm 0.6$ (range $2+$ to $4+$ ). TAPSE was measured by 2-dimensional echocardiography from the apical 4-chamber view at the right ventricular free wall level, as described by Kaul and colleagues. ${ }^{13}$ Finally, right ventricular ejection fraction (RVEF) was calculated after TAPSE analysis from an apical 4-chamber view, according to Kaul and colleagues ${ }^{13}$ and Ueti and colleagues. ${ }^{14}$ Mitral valve repair was considered successful at intraoperative transesophageal echocardiography if there was no residual mitral regurgitation after cardiopulmonary bypass discontinuation with an achieved adequate preload (central venous pressure $10-15 \mathrm{~mm} \mathrm{Hg}$ ). All patients also had intraoperative assessment of left ventricular function. Postoperatively, transthoracic echocardiography was re- peated before discharge, at early follow-up (6 months), and at the end of follow-up. Mean follow-up was 22.3 \pm 14.8 months (range 6-55 months). Recurrence of CIMR was defined as $2+/ 4+$ grade or greater mitral regurgitation at any time postoperatively at semiquantitative color-flow Doppler analysis and recorded in the institutional database. Follow-up was closed on April 1, 2008, and was $100 \%$ completed.

\section{Clinical Assessment}

NYHA was determined preoperatively, up to 5 days before surgery, at discharge, at 6 months, and at the end of follow-up in the outpatient clinic. As a surrogate outcome of heart failure, need and dose of furosemide were assessed at the same time points. Deaths and episodes of acute congestive heart failure, hospital readmission, and redo mitral/coronary surgery during the follow-up were recorded.

\section{Statistical Analysis}

Statistical analysis was performed by the Statistical Program for the Social Sciences for Windows, version 13.0 (SPSS Inc, Chicago, Ill). Continuous variables are presented as mean \pm standard deviation, and categoric variables are presented as absolute numbers or percentages. Normally distributed continuous variables were compared using the unpaired $t$ test, whereas the Mann-Whitney $U$ test was used for not normally distributed variables. Categoric variables were analyzed using the chi-square or Fisher's exact test. Comparison between and within groups was made using 2-way analysis of variance for repeated measures. Follow-up survival and freedom from congestive heart failure, hospital readmission, and redo surgery were determined with Kaplan-Meier life table analysis. Log-rank test was performed to ascertain differences between patients with and without CIMR recurrence.

\section{RESULTS}

\section{Hospital Outcome}

Preoperative and intraoperative data are reported in Table 1. Two patients demonstrated persistent intraoperative 1 to $2+$ CIMR despite 2-size undersizing and underwent mitral valve replacement after reestablishment of cardiopulmonary bypass. These 2 patients were excluded from the study because of the different surgical therapy. Successful mitral valve repair was achieved in all the remaining 64 patients, regardless of the degree of leaflet tethering. Therefore, only 64 patients were enrolled and followed up. Mean mitral ring size was $25.8 \pm 1.6 \mathrm{~mm}$ (median size $26 \mathrm{~mm}$; range 24 $32 \mathrm{~mm}$ ). There were no cases of systolic anterior motion or significant mitral stenosis (mean transvalvular gradient, 4.6 $\pm 0.4 \mathrm{~mm} \mathrm{Hg}$; mean mitral valve area, $2.8 \pm 0.9 \mathrm{~cm}^{2}$ ). Sixteen patients $(25.0 \%)$ underwent tricuspid annuloplasty. Mean tricuspid ring size was $27.5 \pm 1.2 \mathrm{~mm}$ (median size $28 \mathrm{~mm}$; range $26-30 \mathrm{~mm}$ ). Postoperative transit-time flowmetry demonstrated good values in all CABG: Left internal thoracic artery to left anterior descending mean flow was $32.2 \pm 15.8 \mathrm{~mL} / \mathrm{min}$ (pulsatile index of $1.6 \pm 1.2$ ); radial artery mean flow was $48.6 \pm 24.3 \mathrm{~mL} / \mathrm{min}$ (pulsatile index of $1.2 \pm 0.8$ ); and saphenous vein mean flow was $34.7 \pm 10.9 \mathrm{~mL} / \mathrm{min}$ (pulsatile index of $1.9 \pm 0.8$ ). Hospital mortality was $6.2 \%$ (4 patients, all showing preoperative $4+$ CIMR). One patient had perioperative acute myocardial infarction $(1.5 \%), 3$ patients had postoperative low output syndromes $(4.6 \%)$ requiring prolonged intraaortic balloon 
pump ( $>48$ hours) and inotropic support with intravenous dobutamine + levosimendan; and 11 patients $(17.2 \%)$ had paroxysmal atrial fibrillation requiring intravenous amiodarone. Two patients $(3.1 \%)$ had pneumonia, 1 patient $(1.5 \%)$ had acute renal failure, and 1 patient $(1.5 \%)$ had cognitive dysfunction. Overall hospital morbidity accounted for 19 patients $(29.6 \%)$. Intensive care stay was $41.2 \pm 8.3$ hours (range 32-84 hours), and hospital stay was $6.8 \pm 2.2$ days.

\section{Follow-up Clinical Outcome}

Mean follow-up was $22.3 \pm 14.8$ months (range 6-55 months). Two patients died of acute congestive heart failure during follow-up, both showing recurrence of CIMR at follow-up, giving a $22.2 \pm 15.3$ months actuarial survival of $96.5 \% \pm 2.5 \%$ (Figure 1, A). Both patients died within the 6-month follow-up period; therefore, 58 patients surviving beyond the sixth month were completely followed up with echocardiography.

Eight patients had congestive heart failure during followup, 10 patients required hospitalization because of cardiac causes, and 2 patients underwent re-revascularization, giving a $21.3 \pm 15.6$ months actuarial freedom from congestive heart failure of $71.6 \% \pm 10.5 \%$ (Figure $1, B$ ), $21.3 \pm 15.7$ months freedom from hospitalization of $65.2 \% \pm 10.7 \%$ (Figure 1 , $C$ ), and $22.1 \pm 15.3$ months freedom from reintervention of $94.2 \pm 4.2$ (Figure 1, D). Recurrence of CIMR $2+$ or greater at echocardiographic follow-up developed in 16 of 60 patients who were discharged from the hospital $(26.6 \%)$. Of these patients, 2 died during early follow-up, as already reported; therefore, $14(24.1 \%)$ of 58 patients surviving more than 6 months had CIMR 2+ or greater, resulting in $22.5 \pm$ 15.8 months of actuarial freedom from CIMR $(58.2 \% \pm$ $9.8 \%$ ) (Figure 2, A). Patients with recurrence of CIMR did not show differences in the type of implanted ring $(8 / 22$ [26.7\%] Physio Ring vs 6/22 [21.4\%] Carpentier-McCarthy-Adams, $P=.438$ ) and the mean ring size (Physio 28.3 $\pm 1.7 \mathrm{~mm}$ vs Carpentier-McCarthy-Adams $29.0 \pm 1.1 \mathrm{~mm}$; $P=.360$ ). Accordingly, residual CIMR did not differ between ring type at discharge (Physio $0.9 \pm 0.6$ vs Carpentier-McCarthy-Adams $0.9 \pm 0.6, P=.965), 6$ months
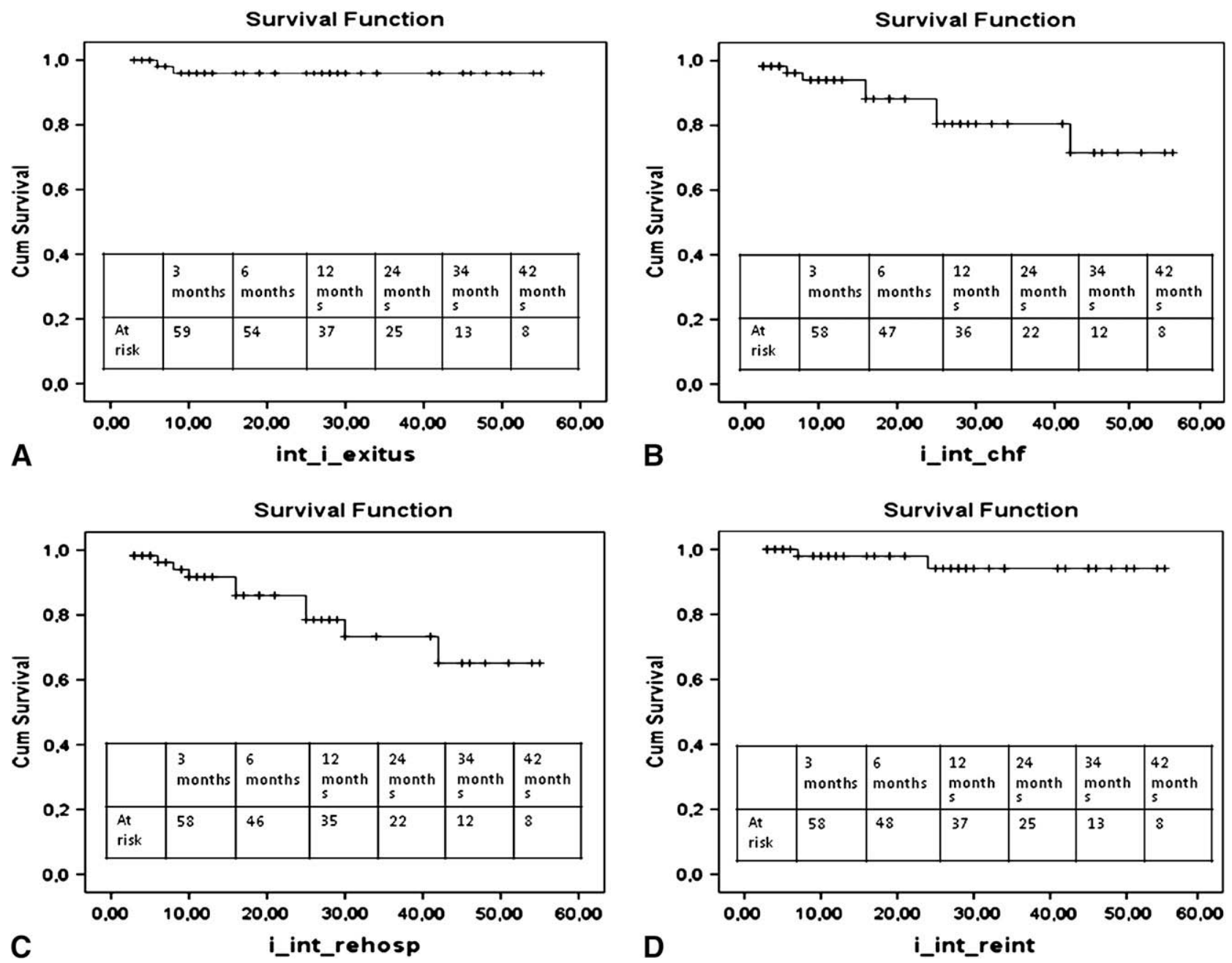

FIGURE 1. Actuarial survival (A), and freedom from CHF (B), hospitalization (C), and reintervention (D). 
A

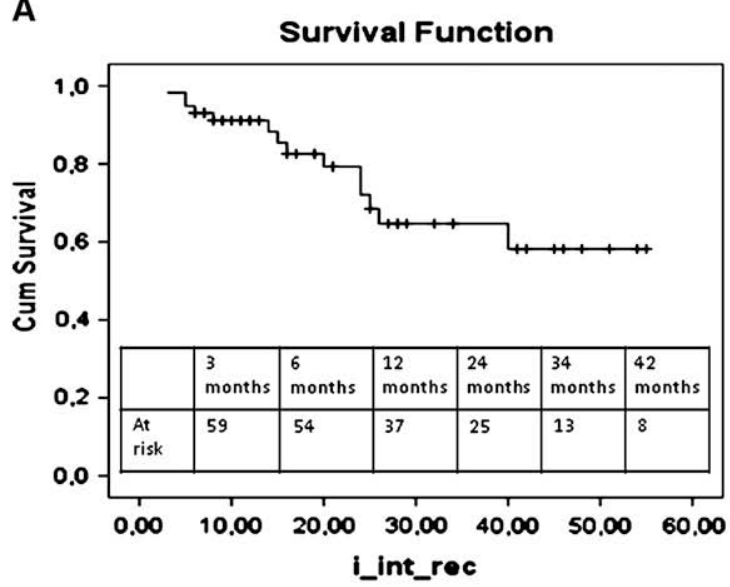

C

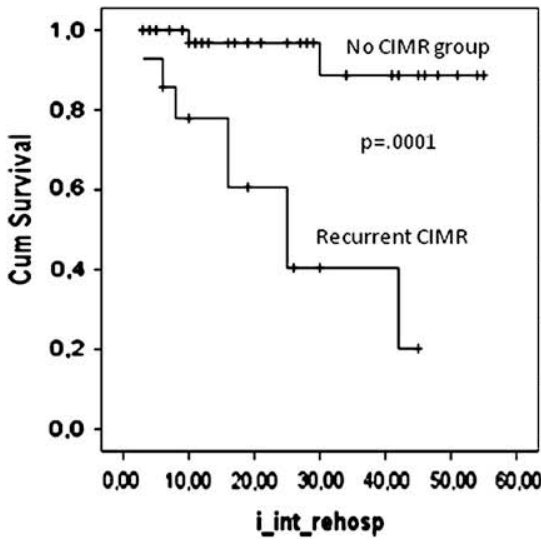

B

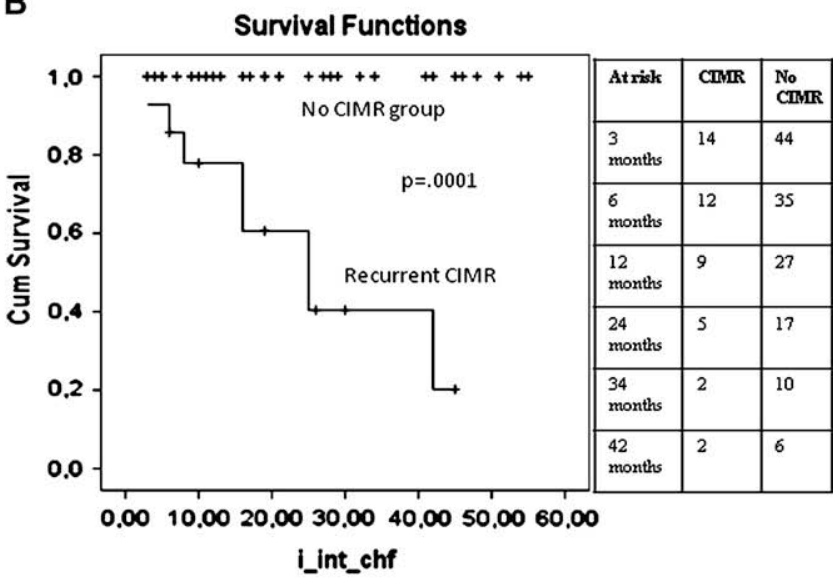

D

\begin{tabular}{|l|l|l|}
\hline At risk & CIMR & $\begin{array}{l}\text { No } \\
\text { CIMR }\end{array}$ \\
\hline $\begin{array}{l}3 \\
\text { months }\end{array}$ & 14 & 44 \\
\hline $\begin{array}{l}6 \\
\text { months }\end{array}$ & 12 & 34 \\
\hline $\begin{array}{l}12 \\
\text { months }\end{array}$ & 9 & 26 \\
\hline $\begin{array}{l}24 \\
\text { months }\end{array}$ & 5 & 17 \\
\hline $\begin{array}{l}34 \\
\text { months }\end{array}$ & 2 & 10 \\
\hline $\begin{array}{l}42 \\
\text { months }\end{array}$ & 2 & 6 \\
\hline
\end{tabular}

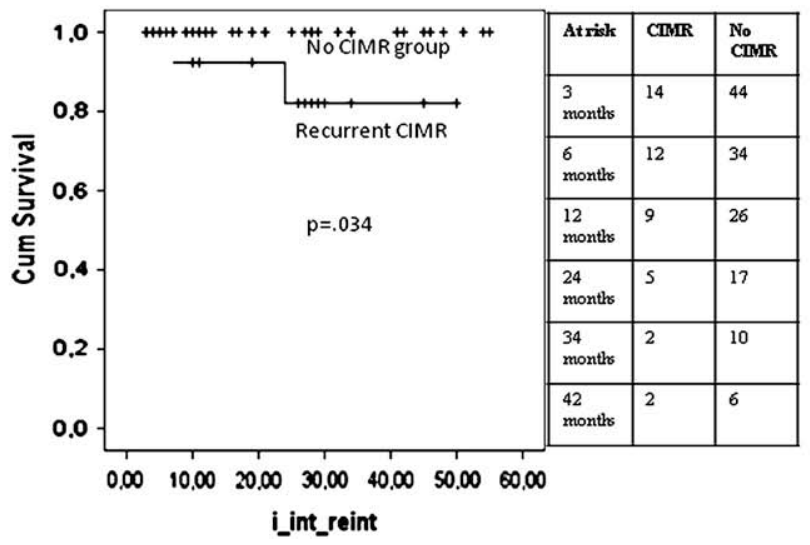

FIGURE 2. Freedom from $\geq 2+$ CIMR recurrence (A) and freedom from CHF (B), hospitalization (C), and reintervention (D) between patients with and without CIMR recurrence. CIMR, Chronic ischemic mitral regurgitation.

(Physio $1.1 \pm 0.6$ vs Carpentier-McCarthy-Adams $0.8 \pm 0.7$ $P=.093$ ), and the end of follow-up (Physio $1.2 \pm 1.0$ vs Carpentier-McCarthy-Adams $0.9 \pm 0.9, P=.182$ ). However, when patients with CIMR were compared with those without CIMR, a significantly lower freedom from CHF (log-rank $P$ $=.0001$; Figure 2, $B)$, hospitalization $(P=.0001$; Figure 2 , $C)$, and reintervention $(P=.034$; Figure $2, D)$ was demonstrated. When functional status was considered, despite the fact that both groups of patients, with or without recurrent
CIMR, improved their NYHA, those without CIMR during follow-up showed significantly better recovery of NYHA and a significantly lower need for diuretics (Table 2). Accordingly, recurrent CIMR induced progressive increase of daily furosemide during the follow-up (Table 2). Finally, when patients with preoperative LVEDD $70 \mathrm{~mm}$ or greater were analyzed, low follow-up freedom from $\mathrm{CHF}$ and hospitalization was found (both $21.2 \% \pm 17.4 \%$ ) (Figure $3, A$ and $B$ ). Moreover, compared with patients with preoperative LVEDD less

TABLE 2. Recovery of New York Heart Association class and need for daily diuretic dose in patients with and without chronic ischemic mitral regurgitation recurrence

\begin{tabular}{|c|c|c|c|c|c|c|}
\hline & Preoperative NYHA & Discharge NYHA & 6-mo NYHA & Follow-up NYHA & $P^{*}$ & $\boldsymbol{P} \dagger$ \\
\hline Recurrent CIMR (14 patients) & $3.7 \pm 0.5$ & $1.8 \pm 0.4$ & $2.1 \pm 0.7$ & $2.6 \pm 0.7$ & .0001 & .000 \\
\hline \multirow[t]{2}{*}{ No CIMR (44 patients) } & $3.3 \pm 0.6$ & $1.6 \pm 0.5$ & $1.4 \pm 0.5$ & $1.0 \pm 0.2$ & .0001 & \\
\hline & $\begin{array}{l}\text { Preoperative daily } \\
\text { furosemide (mg) }\end{array}$ & $\begin{array}{l}\text { Discharge daily } \\
\text { furosemide (mg) }\end{array}$ & $\begin{array}{c}\text { 6-mo daily } \\
\text { furosemide (mg) }\end{array}$ & $\begin{array}{l}\text { Follow-up daily } \\
\text { furosemide (mg) }\end{array}$ & $P^{*}$ & $\boldsymbol{P} \dagger$ \\
\hline Recurrent CIMR (14 patients) & $94.6 \pm 49.2$ & $41.1 \pm 15.8$ & $60.7 \pm 27.2$ & $82.1 \pm 28.5$ & .0001 & .000 \\
\hline No CIMR (44 patients) & $73.8 \pm 25.8$ & $29.5 \pm 10.8$ & $20.4 \pm 6.1$ & $15.6 \pm 8.5$ & .003 & \\
\hline
\end{tabular}

CIMR , Chronic ischemic mitral regurgitation. *Statistical probability within group. $\dagger$ Statistical probability between groups. 

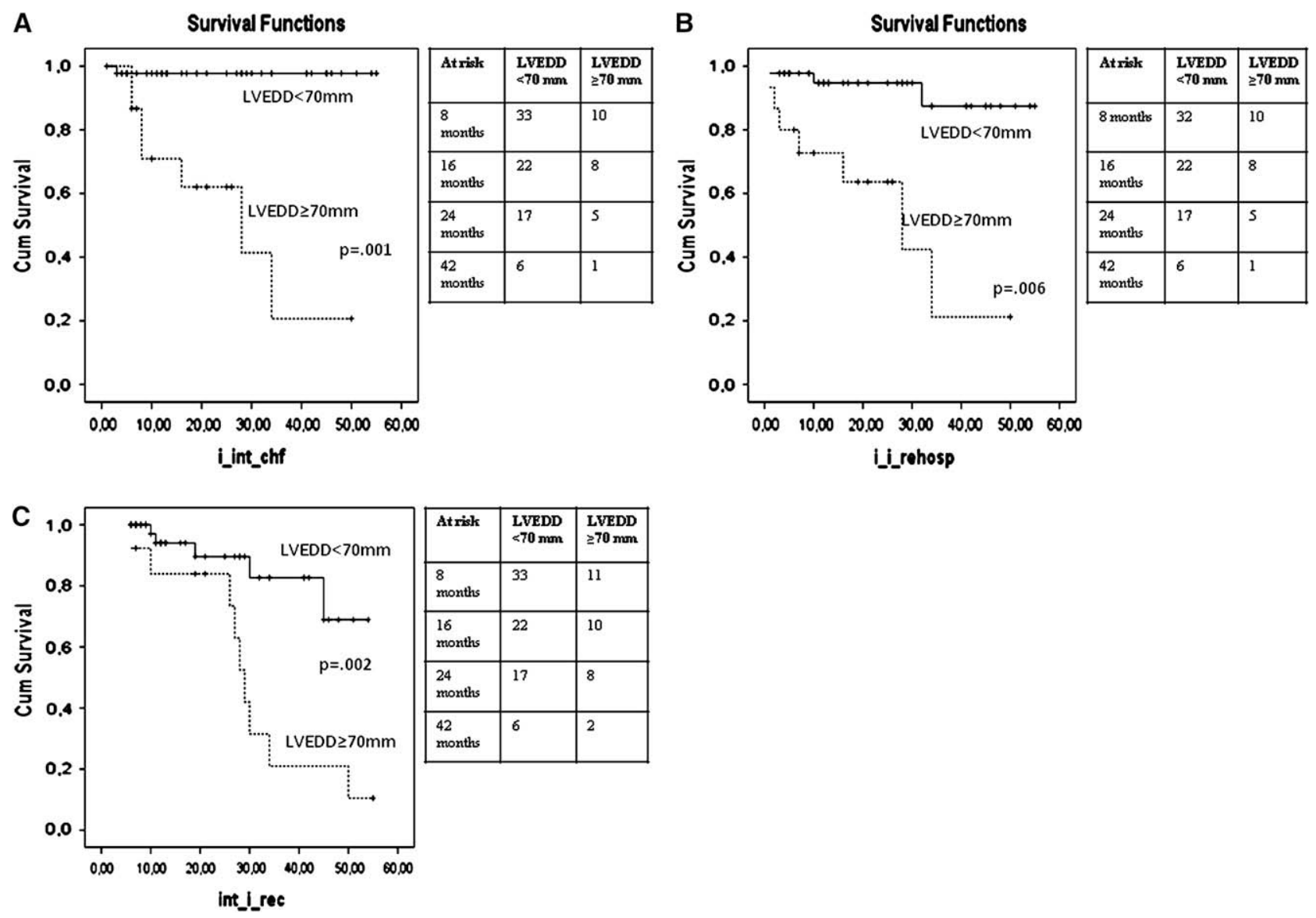

FIGURE 3. Actuarial freedom from CHF (A), hospitalization (B), and recurrent CIMR (C) between patients with preoperative LVEDD $\geq 70 \mathrm{~mm}$ and patients with preoperative LVEDD $<70 \mathrm{~mm}$. $L V E D D$, Left ventricular end-diastolic diameter.

than $70 \mathrm{~mm}$, a significantly lower freedom from CHF $(P=$ .001 ; Figure 3, $A)$ and hospitalization $(P=.006$; Figure 3, $B)$, together with a higher recurrence of CIMR $(P=.002$; Figure 3,C), was shown.

\section{Echocardiographic Results}

A different pattern of left ventricular results was found in patients with recurrent CIMR and patients without CIMR. In particular, patients with CIMR correlated with absence of reverse remodeling of LAD, LVEDD, LVESD, and LVMi (Table 3). Accordingly, LVEF did not improve during follow-up (Table 3). However, after a significant improvement of mitral CD at discharge, $\mathrm{CD}$ increased parallel to the worsening of CIMR, whereas transmitral mean $\Delta \mathrm{p}$ diminished (Table 3).

On the other hand, patients without CIMR showed significant reverse remodeling of LVEDD, LVESD, and LVMi together with improvement of their LVEF and persistently shortened CD from discharge to the end of follow-up. These same patients also showed a higher mean $\Delta \mathrm{p}$ (compared with patients with recurrent CIMR), which remained stable during follow-up and is potentially responsible for the ab- sence of LAD reverse remodeling (Table 3). However, apart from preoperative LVMi, no significant differences were found in baseline clinical and echocardiographic characteristics between patients with recurrent CIMR and patients without CIMR (Table 4).

When right ventricular echocardiographic results were analyzed, despite the fact that TI improved both in patients with and without recurrent CIMR, neither group showed any right-sided heart amelioration in terms of PAPs, RVEF, and TAPSE (Table 5). In particular, patients with recurrent CIMR evidenced a slight progressive worsening of PAPs and a slight deterioration of RVEF (although not statistically significant), without improvement of TAPSE during the follow-up. On the other hand, although patients without CIMR did not show any improvement in PAPs, RVEF, and TAPSE during follow-up, despite the postoperative reduction of TI grade, they did not have deterioration of PAPs, RVEF, and TAPSE (Table 5).

\section{Stratification According to Tricuspid Surgery}

Subgroup analysis in patients who did not undergo tricuspid surgery at the time of RMA demonstrated significant 
TABLE 3. Left-sided heart echocardiographic results

\begin{tabular}{|c|c|c|c|c|c|c|}
\hline & Preoperative CIMR & Discharge CIMR & 6-mo CIMR & Follow-up CIMR & $P^{*}$ & $\boldsymbol{P} \dagger$ \\
\hline Recurrent CIMR (14 patients) & $3.5 \pm 0.5$ & $1.3 \pm 0.5$ & $1.9 \pm 0.3$ & $2.5 \pm 0.5$ & .381 & .0001 \\
\hline \multirow[t]{2}{*}{ No CIMR (44 patients) } & $3.3 \pm 0.5$ & $0.7 \pm 0.5$ & $0.6 \pm 0.5$ & $0.6 \pm 0.5$ & .0001 & \\
\hline & Preoperative LAD & Discharge LAD & 6-mo LAD & Follow-up LAD & $P^{*}$ & $\boldsymbol{P} \dagger$ \\
\hline Recurrent CIMR (14 patients) & $46.6 \pm 5.4$ & $46.6 \pm 5.4$ & $47.1 \pm 5.4$ & $43.7 \pm 12.1$ & .101 & .296 \\
\hline \multirow[t]{2}{*}{ No CIMR (44 patients) } & $45.8 \pm 3.7$ & $45.3 \pm 3.5$ & $44.2 \pm 3.4$ & $43.4 \pm 3.4$ & .087 & \\
\hline & Preoperative LVEDD & Discharge LVEDD & 6-mo LVEDD & Follow-up LVEDD & $P^{*}$ & $\boldsymbol{P} \dagger$ \\
\hline Recurrent CIMR (14 patients) & $67.0 \pm 8.0$ & $67.1 \pm 8.1$ & $67.4 \pm 7.9$ & $67.6 \pm 7.9$ & .212 & .004 \\
\hline \multirow[t]{2}{*}{ No CIMR (44 patients) } & $63.8 \pm 4.8$ & $62.6 \pm 4.7$ & $61.3 \pm 4.5$ & $60.4 \pm 5.1$ & .0001 & \\
\hline & Preoperative LVESD & Discharge LVESD & 6-mo LVESD & Follow-up LVESD & $P^{*}$ & $\boldsymbol{P} \dagger$ \\
\hline Recurrent CIMR (14 patients) & $55.1 \pm 13.3$ & $55.1 \pm 13.2$ & $55.2 \pm 13.4$ & $55.4 \pm 13.1$ & .748 & .014 \\
\hline \multirow[t]{2}{*}{ No CIMR (44 patients) } & $54.6 \pm 6.4$ & $49.5 \pm 6.4$ & $47.9 \pm 6.2$ & $46.9 \pm 5.8$ & .0001 & \\
\hline & Preoperative LVMi & Discharge LVMi & 6-mo LVMi & Follow-up LVMi & $P^{*}$ & $\boldsymbol{P} \dagger$ \\
\hline Recurrent CIMR (14 patients) & $145.3 \pm 19.2$ & $145.2 \pm 19.2$ & $145.9 \pm 19.9$ & $146.4 \pm 18.7$ & .123 & .005 \\
\hline \multirow[t]{2}{*}{ No CIMR (44 patients) } & $138.8 \pm 20.1$ & $138.3 \pm 19.8$ & $136.4 \pm 19.8$ & $134.9 \pm 19.6$ & .002 & \\
\hline & Preoperative LVEF & Discharge LVEF & 6-mo LVEF & Follow-up LVEF & $P^{*}$ & $\boldsymbol{P} \dagger$ \\
\hline Recurrent CIMR (14 patients) & $38.1 \pm 8.7$ & $35.4 \pm 8.1$ & $37.3 \pm 9.3$ & $36.7 \pm 8.7$ & .703 & .0024 \\
\hline \multirow[t]{2}{*}{ No CIMR (44 patients) } & $40.1 \pm 6.9$ & $38.1 \pm 6.8$ & $42.9 \pm 6.5$ & $46.6 \pm 6.7$ & .0001 & \\
\hline & Preoperative CD & Discharge CD & 6-mo CD & Follow-up CD & $P^{*}$ & $\boldsymbol{P} \dagger$ \\
\hline Recurrent CIMR (14 patients) & $1.3 \pm 0.1$ & $0.7 \pm 0.1$ & $0.8 \pm 0.2$ & $0.8 \pm 0.2$ & .001 & .0001 \\
\hline \multirow[t]{2}{*}{ No CIMR (44 patients) } & $1.3 \pm 0.1$ & $0.4 \pm 0.1$ & $0.4 \pm 0.1$ & $0.5 \pm 0.1$ & .0001 & \\
\hline & Preoperative mean $\Delta \mathrm{p}$ & Discharge mean $\Delta \mathrm{p}$ & 6-mo mean $\Delta p$ & Follow-up mean $\Delta p$ & $P^{*}$ & $\boldsymbol{P} \dagger$ \\
\hline Recurrent CIMR (14 patients) & $0.9 \pm 0.8$ & $4.8 \pm 0.8$ & $4.2 \pm 0.8$ & $3.8 \pm 1.0$ & .001 & .0001 \\
\hline No CIMR (44 patients) & $0.9 \pm 0.7$ & $5.8 \pm 1.1$ & $5.7 \pm 1.1$ & $5.8 \pm 1.1$ & .0001 & \\
\hline
\end{tabular}

$C I M R$, Chronic ischemic mitral regurgitation; $L A D$, left atrial diameter; $L V E D D$, left ventricular diastolic diameter; $L V E S D$, left ventricular systolic diameter; $L V M i$, left ventricular mass index; $L V E F$, left ventricular ejection fraction; $C D$, coaptation depth; $\Delta p$, pressure gradient. *Statistical probability within group. $\dagger$ Statistical probability between groups.

differences in right-sided heart echocardiographic parameters during follow-up. In particular, patients developing recurrence of CIMR demonstrated a progressive worsening of TI grade (after an initial early amelioration), with depressed RVEF and TAPSE and high PAPs, whereas patients without CIMR showed a progressive improvement of TI grade, PAPs, RVEF, and TAPSE (Table 6). Obviously, patients with recurrent CIMR demonstrated progressive worsening of NYHA with a greater need for daily diuretics, whereas patients without CIMR progressively improved their NYHA and decreased their daily diuretic dose (Table 6).

On the other hand, patients undergoing tricuspid annuloplasty did not demonstrate any improvement of PAPs, RVEF, and TAPSE during follow-up, regardless of the recurrence of CIMR. However, in those without CIMR, the absence of recurrent CIMR together with the effects of the tricuspid annuloplasty improved TI grade during follow-up (Table 7), with a significant amelioration of NYHA and a significant reduction of the daily diuretic dose, compared with patients with recurrent CIMR (Table 7).

\section{DISCUSSION}

CIMR is considered to be a common cause of postmyocardial infarction congestive heart failure and has been considered one of the few targets for therapeutic opportunities in patients with heart failure. ${ }^{5}$ According to the complex and different pathogenetic mechanisms underlying such disease, several different surgical techniques have been developed for CIMR, from RMA to mitral valve replacement, chordal cutting, papillary imbrication, sling, and repositioning to percutaneous annuloplasty and so on, the majority of which are still considered experimental. ${ }^{2,5,7}$

Because of the safety and reproducibility of RMA, our operative mortality $(6 \%)$ is in line with other studies and well below the logistic European System for Cardiac Operative Risk Evaluation for this group. ${ }^{7}$ Moreover, our favorable overall midterm outcome with a 2-year actuarial survival of $96 \%$ is better than that reported by Grossi and colleagues ${ }^{15}$ but comparable to that reported by others. ${ }^{16,17}$ On the other hand, it is well known that patients with CIMR have a worse natural history than patients with ischemic heart disease 
TABLE 4. Preoperative clinical and echocardiographic characteristics between patients who survived more than 6 months with recurrent chronic ischemic mitral regurgitation and patients without chronic ischemic mitral regurgitation

\begin{tabular}{|c|c|c|c|}
\hline Variables & $\begin{array}{c}\text { Recurrent CIMR } \\
\text { (14 patients) }\end{array}$ & $\begin{array}{c}\text { No CIMR } \\
\text { (44 patients) }\end{array}$ & $\mathbf{P}$ \\
\hline Age, $y$ & $68.3 \pm 3.1$ & $70.2 \pm 2.1$ & .661 \\
\hline Sex (male) & $8(57.1 \%)$ & $28(63.6 \%)$ & .447 \\
\hline Diabetes & $8(57.1 \%)$ & $20(45.5 \%)$ & .324 \\
\hline Hypertension & $4(28.6 \%)$ & $11(25.0 \%)$ & .521 \\
\hline Emergency & $2(14.3 \%)$ & - & .055 \\
\hline Left main stem disease & $11(78.6 \%)$ & $30(68.2 \%)$ & .351 \\
\hline COPD & $9(64.3 \%)$ & $26(59.1 \%)$ & .492 \\
\hline Canadian class score & $3.0 \pm 0.4$ & $3.1 \pm 0.7$ & .717 \\
\hline NYHA & $3.7 \pm 0.5$ & $3.3 \pm 0.6$ & .083 \\
\hline No. CABG & $1.8 \pm 1.0$ & $2.1 \pm 0.8$ & .625 \\
\hline ACC time (min) & $72.5 \pm 4.9$ & $73.2 \pm 4.0$ & .568 \\
\hline CPB time (min) & $137.5 \pm 17.2$ & $134.9 \pm 10.9$ & .508 \\
\hline CIMR grade & $3.5 \pm 0.5$ & $3.3 \pm 0.5$ & .293 \\
\hline LAD & $46.6 \pm 5.4$ & $45.8 \pm 3.7$ & .543 \\
\hline LVEDD & $67.0 \pm 8.0$ & $63.8 \pm 4.8$ & .081 \\
\hline LVESD & $55.1 \pm 13.3$ & $54.6 \pm 6.4$ & .087 \\
\hline LVMi & $145.3 \pm 19.2$ & $138.8 \pm 20.1$ & .039 \\
\hline LVEF & $38.1 \pm 8.7$ & $40.1 \pm 6.9$ & .386 \\
\hline $\mathrm{CD}$ & $1.3 \pm 0.1$ & $1.3 \pm 0.1$ & .919 \\
\hline Mean transmitral $\Delta \mathrm{p}$ & $0.9 \pm 0.8$ & $0.9 \pm 0.7$ & .813 \\
\hline TI grade & $2.1 \pm 0.6$ & $1.9 \pm 0.5$ & .590 \\
\hline PAPs & $38.5 \pm 9.2$ & $37.4 \pm 6.5$ & .635 \\
\hline TAPSE & $16.1 \pm 2.6$ & $15.9 \pm 2.3$ & .774 \\
\hline RVEF & $39.3 \pm 8.8$ & $40.5 \pm 9.6$ & .672 \\
\hline
\end{tabular}

COPD, Chronic obstructive pulmonary disease; $N Y H A$, New York Heart Association; $A C C$, aortic crossclamp; $C P B$, cardiopulmonary bypass; $C I M R$, chronic obstructive pulmonary disease; $L A D$, left atrial diameter; $L V E D D$, left ventricular end-diastolic volume; $L V E S D$, left ventricular end-systolic volume; $L V M i$, indexed left ventricular mass; $L V E F$, left ventricular ejection fraction; $C D$, coaptation depth; $T I$, tricuspid insufficiency; PAPs, systolic pulmonary arterial pressure; TAPSE, tricuspid annular plane systolic excursion; $R V E F$, right ventricular ejection fraction.

without CIMR. A study of 11,748 patients who underwent cardiac catheterization revealed that severe CIMR was associated with a 1 -year mortality of $40 \%$, moderate CIMR of $17 \%$, and mild CIMR of $10 \% .{ }^{18}$ The SAVE study demonstrated that mild chronic CIMR increases the risk of cardiovascular mortality $(29 \%$ vs $12 \%)$ and heart failure ( $24 \%$ vs $16 \%$ ) than patients without CIMR at a mean of 3.5 years after myocardial infarction. Adjustment for differences in baseline characteristics revealed that mild-to-moderate CIMR strongly predicted midterm mortality. ${ }^{19}$ Therefore, it is not surprising that patients with recurrent CIMR showed lower survival, freedom from $\mathrm{CHF}$, hospitalization, and reintervention, together with a progressive worsening of their NYHA and need for diuretics, when compared with patients without recurrences. Our findings correlated with those of De Bonis and colleagues, ${ }^{20}$ showing a significantly worse NYHA when CIMR recurs, and of Gelsomino and colleagues, ${ }^{21}$ who also found higher NYHA class and reoperation rate in patients with failed RMA.
RMA has been successfully used by Bolling and colleagues $^{22}$ for more than a decade. Despite the enthusiasm for the low perioperative mortality rates and the positive effects on survival, CHF, and functional NYHA class, several studies have clearly addressed that RMA is affected by a variable recurrence rate. ${ }^{2,5,7,15-21}$ A recent article examined 585 patients undergoing RMA over a 17 -year period: In $28 \%$ of patients, moderate or more mitral regurgitation developed 6 months postoperatively, an incidence that is similar to that described by other investigators. ${ }^{23}$ Although recurrence tends to occur early postoperatively with relatively low recurrence rates thereafter, ${ }^{24}$ progressive ventricular dilation and ongoing cardiomyopathy seem to be responsible for recurrence rate during follow-up. ${ }^{7,21,24-26}$ Preoperative highly remodeled left ventricles are considered to have a poor success rate at follow-up: Braun and colleagues ${ }^{7}$ showed preoperative LVEDD greater than $65 \mathrm{~mm}$ to correlate with higher recurrence of CIMR with worse survival and NYHA class. Gelsomino and colleagues ${ }^{21}$ found large ventricular volumes and high sphericity index to be predictive of an absence of reverse remodeling and a higher recurrence rate. Roshanali and colleagues ${ }^{25}$ showed preoperative interpapillary muscle distance to be related to recurrent CIMR during follow-up. Calafiore and colleagues ${ }^{26}$ demonstrated high preoperative $\mathrm{CD}$ more than $10 \mathrm{~mm}$ to correlate with recurrence. We found $24 \%$ CIMR recurrence, with a slightly lower freedom from CIMR during follow-up compared with previous studies, ${ }^{2,7,21,23}$ possibly because of the slightly worse profile of preoperative echocardiographic parameters of our population (LVEDD 64-67 $\mathrm{mm}$ and CD $>13 \mathrm{~mm}$ in almost all patients). According to previous series, ${ }^{2,7,21,24-26}$ our patients demonstrating recurrent CIMR showed slightly higher preoperative LVEDD and LVESD, confirming that a higher degree of preoperative ventricular remodeling may correlate with RMA failure. Furthermore, according to Braun and colleagues, ${ }^{7}$ successful RMA cured CIMR, also correlating with reverse remodeling of LVEDD, LVESD, and LVMi in our population. However, whether the recurrence of CIMR anticipates the absence of reverse remodeling of LVEDD, LVESD, and LVMi, or the absence of reverse remodeling of LVEDD, LVESD, and LVMi determines the recurrence of CIMR should be the topic of future studies. Moreover, we found a different pattern of echocardiographic CD and mean transmitral $\Delta \mathrm{p}$ in patients with or without recurrence. In particular, patients without CIMR showed lower $C D$ at discharge, parallel to high mean $\Delta \mathrm{p}$. Both indexes remained stable during follow-up. On the other hand, patients in whom RMA failed demonstrated deeper CD at discharge with a low mean transmitral $\Delta \mathrm{p}$, which worsened further during followup. These data confirm $\mathrm{CD}$ as a reliable index of recurrent CIMR. ${ }^{25,26}$ Moreover, subgroup analysis in patients with preoperative severe dilation of the left ventricle (LVEDD $>70 \mathrm{~mm}$ ) confirmed that these patients, as previously described, ${ }^{7}$ had a worse prognosis in terms of CHF. 
TABLE 5. Right-sided heart echocardiographic results

\begin{tabular}{|c|c|c|c|c|c|c|}
\hline & Preoperative TI & Discharge TI & 6-mo TI & Follow-up TI & $P^{*}$ & $\boldsymbol{P} \dagger$ \\
\hline Recurrent CIMR (14 patients) & $2.1 \pm 0.6$ & $1.1 \pm 0.3$ & $1.1 \pm 0.3$ & $1.2 \pm 0.4$ & .001 & .540 \\
\hline \multirow[t]{2}{*}{ No CIMR (44 patients) } & $1.9 \pm 0.5$ & $1.1 \pm 0.2$ & $1.1 \pm 0.2$ & $1.1 \pm 0.4$ & .001 & \\
\hline & Preoperative PAPs & Discharge PAPs & 6-mo PAPs & Follow-up PAPs & $P^{*}$ & $\boldsymbol{P} \dagger$ \\
\hline Recurrent CIMR (14 patients) & $38.5 \pm 9.2$ & $36.3 \pm 7.4$ & $39.5 \pm 6.9$ & $40.8 \pm 6.6$ & .788 & .353 \\
\hline \multirow[t]{2}{*}{ No CIMR (44 patients) } & $37.4 \pm 6.5$ & $35.2 \pm 5.9$ & $36.6 \pm 6.9$ & $38.4 \pm 7.3$ & .261 & \\
\hline & Preoperative TAPSE & Discharge TAPSE & 6-mo TAPSE & Follow-up TAPSE & $P^{*}$ & $\boldsymbol{P} \dagger$ \\
\hline Recurrent CIMR (14 patients) & $16.1 \pm 2.6$ & $15.6 \pm 2.6$ & $15.8 \pm 2.5$ & $15.9 \pm 2.6$ & .105 & .793 \\
\hline \multirow[t]{2}{*}{ No CIMR (44 patients) } & $15.9 \pm 2.3$ & $15.1 \pm 2.2$ & $15.7 \pm 1.9$ & $16.1 \pm 2.1$ & .083 & \\
\hline & Preoperative RVEF & Discharge RVEF & 6-mo RVEF & Follow-up RVEF & $P^{*}$ & $\boldsymbol{P} \dagger$ \\
\hline Recurrent CIMR (14 patients) & $39.3 \pm 8.8$ & $37.3 \pm 8.6$ & $38.8 \pm 8.2$ & $37.3 \pm 8.6$ & .207 & \\
\hline No CIMR (44 patients) & $40.5 \pm 9.6$ & $39.5 \pm 9.9$ & $40.2 \pm 9.8$ & $40.5 \pm 9.8$ & .149 & 637 \\
\hline
\end{tabular}

$T I$, Tricuspid insufficiency; PAPS, systolic pulmonary arterial pressure; TAPSE, tricuspid annular plane systolic excursion. *Statistical probability within group. $\dagger$ Statistical probability between groups.

If general agreement exists on the beneficial effects of RMA on left ventricular remodeling, little is known of the fate of the right chambers. A recent study showed the potential of RMA to induce iatrogenic mitral stenosis. ${ }^{8}$ Functional TI is often associated with mitral valve disease and thought to be caused by dilatation of the tricuspid annulus and tethering of the tricuspid leaflets resulting from right ventricular dilatation. ${ }^{27}$ Functional tricuspid regurgitation is now en- countered regularly in patients with severe left ventricular dysfunction who undergo cardiac operations. ${ }^{7,8,28-32}$ Tricuspid annuloplasty represents the common surgical strategy, although the rate of recurrent regurgitation remains high. ${ }^{28,29}$ Moreover, most of the data available on the outcome of functional tricuspid regurgitation after mitral surgery come from series of patients affected by degenerative $^{28}$ or rheumatic mitral disease, ${ }^{30}$ whereas only few

TABLE 6. Right-sided heart echocardiographic and functional results in patients without tricuspid annuloplasty

\begin{tabular}{|c|c|c|c|c|c|c|}
\hline & Preoperative TI & Discharge TI & 6-mo TI & Follow-up TI & $P^{*}$ & $\boldsymbol{P} \dagger$ \\
\hline Recurrent CIMR (8 patients) & $1.8 \pm 0.4$ & $1.1 \pm 0.3$ & $1.3 \pm 0.5$ & $1.8 \pm 0.7$ & .013 & .0001 \\
\hline \multirow[t]{2}{*}{ No CIMR (34 patients) } & $1.8 \pm 0.4$ & $1.0 \pm 0.2$ & $1.0 \pm .02$ & $1.0 \pm 0.1$ & .0001 & \\
\hline & Preoperative PAPs & Discharge PAPs & 6-mo PAPs & Follow-up PAPs & $P^{*}$ & $\boldsymbol{P} \dagger$ \\
\hline Recurrent CIMR (8 patients) & $35.9 \pm 8.2$ & $34.2 \pm 5.6$ & $35.8 \pm 4.7$ & $35.0 \pm 7.9$ & .336 & .000 \\
\hline \multirow[t]{2}{*}{ No CIMR (34 patients) } & $37.9 \pm 5.1$ & $30.8 \pm 3.8$ & 28. \pm 4.2 & $27.6 \pm 3.7$ & .0001 & \\
\hline & Preoperative TAPSE & Discharge TAPSE & 6-mo TAPSE & Follow-up TAPSE & $P^{*}$ & $\boldsymbol{P} \dagger$ \\
\hline Recurrent CIMR (8 patients) & $17.0 \pm 2.8$ & $16.8 \pm 2.9$ & $16.8 \pm 2.8$ & $16.9 \pm 2.9$ & .555 & .000 \\
\hline \multirow[t]{2}{*}{ No CIMR (34 patients) } & $15.1 \pm 2.5$ & $15.2 \pm 2.3$ & $16.8 \pm 2.1$ & $18.3 \pm 2.3$ & .0001 & \\
\hline & Preoperative RVEF & Discharge RVEF & 6-mo RVEF & Follow-up RVEF & $P^{*}$ & $\boldsymbol{P} \dagger$ \\
\hline Recurrent CIMR (8 patients) & $44.5 \pm 8.8$ & $39.4 \pm 8.7$ & $40.7 \pm 8.5$ & $39.3 \pm 8.6$ & .073 & .0001 \\
\hline \multirow[t]{2}{*}{ No CIMR (34 patients) } & $44.8 \pm 7.9$ & $45.0 \pm 8.5$ & $48.3 \pm 8.8$ & $48.8 \pm 8.4$ & .009 & \\
\hline & Preoperative NYHA & Discharge NYHA & 6-mo NYHA & Follow-up NYHA & $P^{*}$ & $\boldsymbol{P} \dagger$ \\
\hline Recurrent CIMR (8 patients) & $3.5 \pm 0.5$ & $1.8 \pm 0.4$ & $2.0 \pm 0.7$ & $2.5 \pm 0.7$ & .003 & .000 \\
\hline \multirow[t]{2}{*}{ No CIMR (34 patients) } & $3.3 \pm 0.6$ & $1.5 \pm 0.5$ & $1.3 \pm 0.5$ & $1.1 \pm 0.3$ & .0001 & \\
\hline & $\begin{array}{c}\text { Preoperative daily } \\
\text { furosemide (mg) }\end{array}$ & $\begin{array}{l}\text { Discharge daily } \\
\text { furosemide }(\mathrm{mg})\end{array}$ & $\begin{array}{c}\text { 6-mo daily } \\
\text { furosemide (mg) }\end{array}$ & $\begin{array}{l}\text { Follow-up daily } \\
\text { furosemide (mg) }\end{array}$ & $P^{*}$ & $\boldsymbol{P} \dagger$ \\
\hline Recurrent CIMR (8 patients) & $77.8 \pm 23.2$ & $36.1 \pm 13.2$ & $50.0 \pm 21.6$ & $75.0 \pm 30.6$ & .008 & .000 \\
\hline No CIMR (34 patients) & $75.7 \pm 25.3$ & $29.5 \pm 11.2$ & $21.2 \pm 5.8$ & $17.0 \pm 8.2$ & .0001 & \\
\hline
\end{tabular}

$T I$, Tricuspid insufficiency; PAPs, systolic pulmonary arterial pressure; TAPSE, tricuspid annular plane systolic excursion. *Statistical probability within group. $\dagger$ Statistical probability between groups. 
TABLE 7. Right-sided heart echocardiographic and functional results in patients with tricuspid annuloplasty

\begin{tabular}{|c|c|c|c|c|c|c|}
\hline & Preoperative TI & Discharge TI & 6-mo TI & Follow-up TI & $P^{*}$ & $\boldsymbol{P} \dagger$ \\
\hline Recurrent CIMR (6 patients) & $2.6 \pm 0.5$ & $1.6 \pm 0.5$ & $1.8 \pm 0.8$ & $2.4 \pm 0.5$ & .411 & .010 \\
\hline \multirow[t]{2}{*}{ No CIMR (10patients) } & $2.5 \pm 0.5$ & $1.3 \pm 0.5$ & $1.3 \pm 0.5$ & $1.3 \pm 0.8$ & .004 & \\
\hline & Preoperative PAPs & Discharge PAPs & 6-mo PAPs & Follow-up PAPs & $P^{*}$ & $\boldsymbol{P} \dagger$ \\
\hline Recurrent CIMR (6 patients) & $49.0 \pm 8.2$ & $41.0 \pm 10.2$ & $45.0 \pm 11.7$ & $45.2 \pm 11.5$ & .854 & .126 \\
\hline \multirow[t]{2}{*}{ No CIMR (10 patients) } & $44.5 \pm 5.7$ & $42.1 \pm 10.1$ & $43.2 \pm 7.5$ & $42.7 \pm 8.4$ & .181 & \\
\hline & Preoperative TAPSE & Discharge TAPSE & 6-mo TAPSE & Follow-up TAPSE & $P^{*}$ & $\boldsymbol{P} \dagger$ \\
\hline Recurrent CIMR (6 patients) & $14.6 \pm 1.1$ & $14.4 \pm 1.2$ & $14.4 \pm 0.8$ & $14.5 \pm 0.7$ & .638 & .300 \\
\hline \multirow[t]{2}{*}{ No CIMR (10 patients) } & $15.5 \pm 1.8$ & $14.7 \pm 1.9$ & $15.4 \pm 1.5$ & $15.5 \pm 1.4$ & .978 & \\
\hline & Preoperative RVEF & Discharge RVEF & 6-mo RVEF & Follow-up RVEF & $P^{*}$ & $\boldsymbol{P} \dagger$ \\
\hline Recurrent CIMR (6 patients) & $31.8 \pm 2.3$ & $30.3 \pm 2.7$ & $32.4 \pm 2.6$ & $33.1 \pm 3.2$ & .218 & .929 \\
\hline \multirow[t]{2}{*}{ No CIMR (10 patients) } & $32.0 \pm 1.9$ & $31.0 \pm 1.8$ & $32.0 \pm 1.9$ & $32.2 \pm 2.2$ & .307 & \\
\hline & Preoperative NYHA & Discharge NYHA & 6-mo NYHA & Follow-up NYHA & $P^{*}$ & $\boldsymbol{P} \dagger$ \\
\hline Recurrent CIMR (6 patients) & $3.9 \pm 0.2$ & $2.0 \pm 0.3$ & $2.4 \pm 0.5$ & $2.8 \pm 0.8$ & .033 & .0001 \\
\hline \multirow[t]{2}{*}{ No CIMR (10 patients) } & $3.6 \pm 0.6$ & $1.7 \pm 0.6$ & $1.4 \pm 0.5$ & $1.1 \pm 0.3$ & .0001 & \\
\hline & $\begin{array}{c}\text { Preoperative daily } \\
\text { furosemide (mg) }\end{array}$ & $\begin{array}{l}\text { Discharge daily } \\
\text { furosemide (mg) }\end{array}$ & $\begin{array}{c}\text { 6-mo daily } \\
\text { furosemide (mg) }\end{array}$ & $\begin{array}{l}\text { Follow-up daily } \\
\text { furosemide (mg) }\end{array}$ & $P^{*}$ & $\boldsymbol{P}_{\dagger}$ \\
\hline Recurrent CIMR (6 patients) & $85.0 \pm 70.0$ & $50.0 \pm 17.6$ & $80.0 \pm 27.4$ & $95.0 \pm 20.9$ & .010 & .0001 \\
\hline No CIMR (10 patients) & $88.2 \pm 27.5$ & $29.5 \pm 10.1$ & $18.2 \pm 6.5$ & $11.4 \pm 8.8$ & .001 & \\
\hline
\end{tabular}

TI, Tricuspid insufficiency; PAPS, systolic pulmonary arterial pressure; TAPSE, tricuspid annular plane systolic excursion; CIMR, chronic obstructive pulmonary disease. * Statistical probability within group. $†$ Statistical probability between groups.

reports deal with regurgitation of the tricuspid valve in the context of dilated cardiomyopathy. ${ }^{8,29}$ Our population substantially showed little impact of RMA on right-sided heart evolution. Obviously, when CIMR recurred, the persistence of the left-sided disease did not ameliorate TI, PAPs, RVEF, and TAPSE, regardless of whether patients underwent tricuspid annuloplasty at the time of RMA. It was recently demonstrated that the progression or recurrence of significant TI occurred among patients who did not show signs of reverse left ventricular remodeling after magnetic resonance angiography for dilated cardiomyopathy. ${ }^{27}$ Di Mauro and colleagues ${ }^{31}$ demonstrated right ventricular dysfunction in patients undergoing RMA, which correlated with worsening NYHA and reduced survival. Accordingly, our patients with failed RMA not only demonstrated the absence of leftheart reverse remodeling but also failed to improve their TI, PAPs, RVEF, and TAPSE. Furthermore, they had to increase their daily dose of diuretics and worsened their NYHA whenever CIMR recurred in patients without previous tricuspid surgery.

On the other hand, patients without CIMR showed a completely different evolution of the right chambers, based on the need for tricuspid surgery at the time of RMA. Patients without CIMR who did not undergo tricuspid annuloplasty at the time of RMA demonstrated progressive amelioration of TI grade, along with PAPs, RVEF, and TAPSE, whereas patients undergoing tricuspid surgery at the time of RMA did not show improved PAPs, RVEF, and TAPSE despite good functional results of the RMA itself. Dreyfus and colleagues $^{32}$ clearly demonstrated that tricuspid annular dilatation is an ongoing process, advocating that any patient with substantial annular dilatation should undergo repair regardless of the TI grade. Matsuyama and associates ${ }^{33}$ reported that $16 \%$ of the patients who underwent mitral valve surgery without concomitant tricuspid valve surgery developed $3+$ to 4+TI at an 8-year follow-up.

\section{CONCLUSIONS}

Our results show that patients undergoing tricuspid surgery have a worse echocardiographic profile compared with those not undergoing tricuspid annuloplasty, being patients with an already compromised right ventricle at the time of surgery (low TAPSE and RVEF, high PAPs). These patients therefore have a reduced possibility of reverse remodeling of the right side of the heart. It is well known that ventricular dilation or severe tethering before surgery anticipates TI recurrence despite annuloplasty. ${ }^{34}$ Moreover, it can be speculated that in this subset of patients, the higher mean transmitral $\Delta \mathrm{p}$ (demonstrated in patients without CIMR during follow-up) may act as a "iatrogenic" mild mitral stenosis, preserving the left ventricle from progressive dilation but further overloading an already diseased right ventricle. ${ }^{8}$ The absence of left ventricular remodeling in patients with a severely dilated left ventricle identifies a more 
advanced "left-sided" stage of the disease (with poor outcome after isolated RMA), where the left ventricle itself needs to be addressed. ${ }^{7}$ Accordingly, it can be hypothesized that the need for tricuspid annuloplasty at the time of RMA identifies a more advanced "right-sided" stage of cardiomyopathy, where tricuspid annuloplasty itself is not sufficient to improve the right side of the heart, further overloaded by an increased pulmonary pressure induced by RMA itself. However, the absence of CIMR together with the effect of tricuspid surgery in this highly diseased category of patients avoids volume overload on an already compromised right ventricle, leading at least to a better NYHA class (and lower diuretic need) compared with patients with CIMR recurrence. Therefore, only patients undergoing mitral surgery without functional tricuspid disease may benefit from RMA alone. However, further studies addressing right heart evolution after RMA in patients with ischemic dilated cardiomyopathy are needed to clarify such a topic.

\section{References}

1. Trichon BH, Glower DD, Shaw LK, Cabell CH, Anstrom KJ, Felker GM, et al. Survival after coronary revascularization, with and without mitral valve surgery, in patients with ischemic mitral regurgitation. Circulation. 2003;108(Suppl 2):II-103-10.

2. Bax JJ, Braun J, Somer ST, Klautz R, Holman ER, Versteegh MI, et al. Restrictive annuloplasty and coronary revascularization in ischemic mitral regurgitation results in reverse left ventricular remodeling. Circulation. 2004;110(Suppl 2):II-104-8.

3. Diodato MD, Moon MR, Pasque MK, Barner HB, Moazami N, Lawton JS, et al. Repair of ischemic mitral regurgitation does not increase mortality or improve long-term survival in patients undergoing coronary artery revascularization: a propensity analysis. Ann Thorac Surg. 2004;78:794-9.

4. Bonow RA, Carabello BA, Chatterjee K. ACC/AHA 2006 guidelines for the management of patients with valvular heart disease: a report of the American College of Cardiology/American Heart Association Task Force on Practice Guidelines. J Am Coll Cardiol. 2006;48:598-675.

5. Borger MA, Alam A, Murphy PM, Doenst T, David TE. Chronic ischemic mitral regurgitation: repair, replace or rethink? Ann Thorac Surg. 2006;81:1153-61.

6. Hung J, Papakostas L, Tahta SA, Hardy BG, Bollen BA, Duran CM, et al. Mechanism of recurrent ischemic mitral regurgitation after annuloplasty. Continued LV remodelling as a moving target. Circulation. 2004;110(11 suppl. 1):II85-90.

7. Braun J, van de Veire NR, Klautz RJM, Versteegh MIM, Holman ER, Westenberg JJM, et al. Restrictive mitral annuloplasty cures ischemic mitral regurgitation and heart failure. Ann Thorac Surg. 2008;85:430-7.

8. Magne J, Senechal M, Mathieu P, Dumesnil JG, Dagenais F, Pibarot P. Restrictive annuloplasty for ischemic mitral regurgitation may induce functional mitral stenosis. J Am Coll Cardiol. 2008;51:1692-701.

9. Byrne JG, Aklog L, Adams DH. Assessment and management of functional or ischemic mitral regurgitation. Lancet. 2000;355:1743-4.

10. Matsunaga A, Duran CMG. Progression of tricuspid regurgitation after repaired functional ischemic mitral regurgitation. Circulation. 2005;112(SI):453-7.

11. Onorati F, Pezzo F, Comi MC, Impiombato B, Esposito A, Polistina M, et al. Radial artery graft function is not affected by age. J Thorac Cardiovasc Surg. 2007; 134:1112-20.

12. Devereux RB, Alonso DR, Lutas EM, Gottlieb GJ, Campo E, Sachs I, et al. Echocardiographic assessment of left ventricular hypertrophy: comparison to necropsy findings. Am J Cardiol. 1986;57:450-8.

13. Kaul S, Tei C, Hopkins JM, Shah PM. Assessment of right ventricular function using two-dimensional echocardiography. Am Heart J. 1984;107:526-31.
14. Ueti OM, Camargo EE, Ueti A de A, deLima-Filho EC, Nogueira EA. Assessment of right ventricular function with Doppler echocardiographic indices derived from tricuspid annular motion: comparison with radionuclide angiography. Heart. 2002;88:244-8

15. Grossi EA, Goldberg JD, LaPietra A, Ye X, Zakow P, Sussman M, et al. Ischemic mitral valve reconstruction and replacement: comparison of longterm survival and complications. J Thorac Cardiovasc Surg. 2001;122:1107-24.

16. Kang D-H, Kim M-J, Kang S-J. Mitral valve repair versus revascularization alone in the treatment of ischemic mitral regurgitation. Circulation. 2006;144: 499-503.

17. Wong DR, Agnihori AK, Hung JW, Vlahakes GJ, Akins CW, Hilgenberg AD, et al. Long-term survival after surgical revascularization for moderate ischemic mitral regurgitation. Ann Thorac Surg. 2005;80:570-7.

18. Hickey MS, Smith LR, Muhlbaier LH, Harrell FE Jr, Reves JG, Hinohara T, et al. Current prognosis of ischemic mitral regurgitation: implications for future management. Circulation. 1988;78(Suppl 1):51-9.

19. Lamas GA, Mitchell GF, Flaker GC, Smith SC Jr, Gersh BJ, Basta L, et al. Clinical significance of mitral regurgitation after acute myocardial infarction. Survival and Ventricular Enlargement Investigators. Circulation. 1997;96:827-33.

20. De Bonis M, Lapenna E, Verzini A, La Canna G, Grimaldi A, Torracca L, et al. Recurrence of mitral regurgitation parallels the absence of left ventricular reverse remodelling after mitral repair in advanced dilated cardiomyopathy. Ann Thorac Surg. 2008;85:932-9.

21. Gelsomino S, Lorusso R, Capecchi I, Rostagno C, Romagnoli S, Billè G, et al Left ventricular reverse remodeling after undersized mitral ring annuloplasty in patients with ischemic regurgitation. Ann Thorac Surg. 2008;85:1319-30.

22. Bolling SF, Deeb GM, Bach DS. Mitral valve reconstruction in elderly, ischemic patients. Chest. 1996;109:35-40.

23. Tahta SA, Oury JH, Maxwell JM, Hiro SP, Duran CM. Outcome after mitral valve repair for functional ischemic mitral regurgitation. J Heart Valve Dis. 2002;11: 11-8.

24. McGee EC, Gillinov AM, Blackstone EH, Rajeswaran J, Cohen G, Najam F, et al Recurrent mitral regurgitation after annuloplasty for functional ischemic mitral regurgitation. J Thorac Cardiovasc Surg. 2004;128:916-24.

25. Roshanali F, Mandegar MH, Yousefnia MA, Rayatzadeh H, Alaeddini F. A prospective study of predicting factors in ischemic mitral regurgitation recurrence after ring annuloplasty. Ann Thorac Surg. 2007;84:745-9.

26. Calafiore AM, Di Mauro M, Gallina S, Di Giammarco G, Iacò AL, Teodori G et al. Mitral valve surgery for chronic ischemic mitral regurgitation. Ann Thorac Surg. 2004;77:1989-97.

27. De Bonis M, Lapenna E, Sorrentino F, La Canna G, Grimaldi A, Maisano F, et al Evolution of tricuspid regurgitation after mitral valve repair for functional mitral regurgitation in dilated cardiomyopathy. Eur J Cardiothorac Surg. 2008;33: 600-6.

28. McCarthy PM, Bhudia SK, Rajeswaran J, Hoercher KJ, Lytle BW, Cosgrove DM et al. Tricuspid valve repair: durability and risk factors for failure. J Thorac Cardiovasc Surg. 2004;127:674-85.

29. Matsunaga A, Duran CM. Progression of tricuspid regurgitation after repaired functional ischemic mitral regurgitation. Circulation. 2005;112:453-7.

30. Izumi C, Iga K, Konishi T. Progression of isolated tricuspid regurgitation late after mitral valve surgery for rheumatic mitral valve disease. J Heart Valve Dis. 2002; 11:353-6.

31. Di Mauro M, Calafiore AM, Penco M, Romano S, Di Giammarco G, Gallina S Mitral valve repair for dilated cardiomyopathy: predictive role of right ventricular dysfunction. Eur Heart J. 2007;28:2510-6.

32. Dreyfus GD, Corbi PJ, Chan KM, Bahrami T. Secondary tricuspid regurgitation or dilatation: which should be the criteria for surgical repair? Ann Thorac Surg 2005;79:127-32.

33. Matsuyama K, Matsumoto M, Sugita T, Nishizawa J, Tokuda Y, Matsuo T. Predictors of residual tricuspid regurgitation after mitral valve surgery. Ann Thorac Surg. 2003;75:1826-8.

34. Fukuda S, Song JM, Gillinov AM, McCarthy PM, Daimon M, Kongsaerepong V, et al. Tricuspid valve tethering predicts residual tricuspid regurgitation after tricuspid annuloplasty. Circulation. 2005;111:975-9. 